\title{
Dr. YouTube will see you now
}

$\mathrm{S}$ ee one, do one, teach one: that's the philosophy behind a new brand of how-to video showcasing self-surgery and other "do it yourself" fixes to medical problems that's gaining traction on the social Web.

Motivated by financial hardship, frustration with lengthy wait times and a desire for a more active role in health care decision-making, an increasing number of people are heading to videosharing websites such as YouTube to study and share at-home solutions to a range of health complaints.

The procedures, performed for the most part by amateurs without such niceties as local anesthetic or sterilized tools, range from the mundane (how to remove stitches) to the dangerously misguided (how to perform makeshift cryosurgery on skin cancer using dry ice).

Despite the inherent risks associated with "backyard medicine," self-treatment often poses less of a "hassle" to patients fed up with navigating costly and complicated medical systems, says Orin Jencks, a Louisiana-based YouTube user whose at-home toenail removal video (one of several hundred on the site) has attracted almost 15000 views (www.youtube.com /watch?v=YRpqJgbpmKM).

"I've seen a lot of people's videos of their toenail removals," he says. "I've had my own removed twice by the doctor, but they kept coming back wrong. I don't have insurance, so I started taking them off myself every couple of months with a pair of pliers or tweezers."

While Jencks plans to have a doctor permanently remove the nails some day, for now, "it's just so expensive and takes so much time and paperwork to get anything done, it's really more of a headache than it's worth to go to the doctor."

Medical care isn't an option for everyone, he explains in response to queries over whether the videos might encourage some to forgo necessary medical attention. "I wouldn't tell just anybody to go out and do what I do if they didn't want

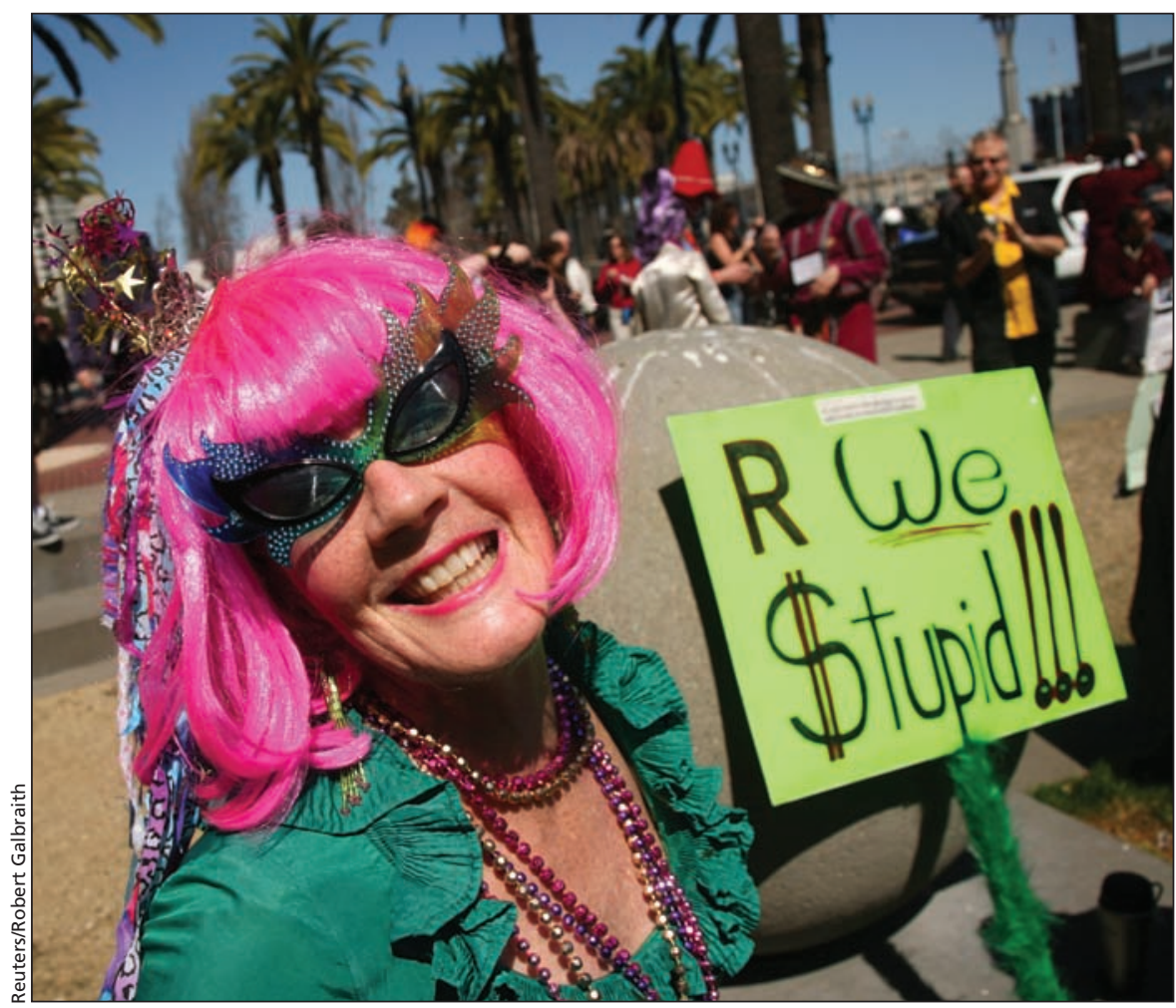

The adage that a doctor who treats himself has a fool for a patient can apply equally to patients who think they hold an MD.

to, and I'm not saying it's the best option, but I've been doing this for years and never had any problem."

The number of people in the United States without health insurance increased to 50.7 million ( $16.7 \%$ of the population) in 2009 from 46.3 million (15.4\%) in 2008. Even those patients with insurance are projected to each cough up \$US4386 in 2011 to cover health insurance premiums and out-of-pocket costs such as copayments and deductibles (www.cmaj .ca/cgi/doi/10.1503/cmaj.109-3713).

When money isn't an object, wait times often are, says Misty Zaugg, a Michigan-based blogger and unlicensed physician whose how-to video on removing stitches got 47672 hits on YouTube (www.youtube.com/watch?v =P7S_y34HUHo). "A lot of people don't want the inconvenience of going to the emergency room. Plus, any time you enter a hospital you run the risk of getting a nosocomial infection."
Today's "informed patient" is also more confident in their own medical abilities, she says. "It wasn't so long ago you couldn't do a pregnancy test without going to the doctor. Now, nobody bats an eye about buying a kit at the store. ... I choose to do almost everything at home, and I'd say half of my medical knowledge I got at medical school and the other half I got online."

Some $78 \%$ of American patients believe they can learn helpful information about their conditions by communicating with other patients over the Internet, according to a Jan. 31, 2010, survey by the Markle Foundation, a New York City, New York-based notfor-profit organization that promotes the use of information technology to resolve health care and national security needs (www.markle.org/publications /1446-public-and-doctors-surveyed-use -social-media-comparable-proportions).

While it can be difficult to separate 
the wheat from the chaff when it comes to online advice, videos give people who are considering self-treatment a better sense of what they're getting into, says Zaugg. "You don't need a lot of medical knowledge to perform certain procedures. In almost all cases, the main risks you run are infection or cutting into something you shouldn't, but that doesn't mean the knowledge should be inaccessible for anyone who wants to put the time and effort into learning. I think everything a doctor learns, your average intelligent person can learn without a degree."

It may be "quite reasonable" to train patients, particularly in remote locations, to remove their own stitches, but one should "never underestimate the ability of people to misinterpret rules or get them wrong," says Dr. Brian Goldman, an emergency room physician at Mount Sinai Hospital in Toronto, Ontario. "The first thing I'd want someone to tell me is how many stitches they had, because if they pulled out eight and are satisfied, when in fact there were nine, they could end up with an infection."

The popularity of medical how-to videos speaks to the "tremendous potential" that exists to teach patients to use health care services more appropriately, he adds. But in their current form, such videos typically fail to mention "anything about the potential complications" or take into account that "everything that seems simple may not be to everybody."

While Canadians are less likely than their American counterparts to "rifle their own medicine cabinets" rather than see a doctor for financial reasons, Goldman says wait times in Canada are motivation enough for some people to shirk professional care.

"A woman I know was scheduled for an appointment at an orthopedic clinic to have surgical pins removed from her foot. She arrived on time for her appointment at eight in the morning, and was kept waiting until four in the afternoon. At one point, she decided she couldn't wait any longer, so she pulled the pins out right there in the clinic and walked away. This is a smart person, and she was willing to do that."

A dearth of research tracking complications among patients who choose to skip the line and treat themselves at home makes it difficult to assess the health impact of open forum access to videos such as those featured in the "YouTube Medical School" series. Created by an orthopedic surgeon to provide practical examples of procedures to medical students "or anyone else who wants to study to be a doctor," the near 600 videos in the series have attracted some 1136850 views (www.youtube .com/user/surgicalgown).

However, a cursory search of patient narratives accompanying 2009 data compiled by the US Consumer Product
Safety Commission's National Electronic Injury Surveillance System reveals a litany of botched attempts to remove leg casts with paint thinner, moles with nail clippers, dry skin with razors and teeth with screwdrivers, among other do-ityourself medicine failures (www.cpsc .gov/cgibin/NEISSQuery/ExportFile.aspx ?FileName=/download/nss20027.tsv).

Most common are the "people who have a lump on their skin and are certain they have an abscess, so they squeeze it," putting themselves at risk of "particularly serious" blood-borne infections, says Goldman. Another category of doit-yourself enthusiast that Goldman frequently comes across in emergency rooms is "the patient who is convinced they have a foreign body, like a sliver, a metallic shard or a piece of glass or wood, which they've attempted to remove themselves. ... Sometimes I can remove it, sometimes I can't and sometimes there's nothing there at all."

While such cases are nothing new, the proliferation of medical how-to videos may lend a sense of false security to people who might otherwise have been on the fence about attempting a procedure at home, Goldman fears. "Suffice it to say, it happens in Canada, it happens in the United States, and I'd be very surprised if it doesn't happen in other countries, both developed and developing." — Lauren Vogel, CMAJ

CMAJ 2011. DOI:10.1503/cmaj.109-3812

\section{"Do it yourself" births prompt alarm}

A growing number of women are choosing to give birth without the assistance of doctors or midwives, provoked by dissatisfaction with modern obstetric care, fear of unnecessary medical intervention and a desire to reclaim birth as a private, natural act.

It's a choice the professionals say is fraught with peril. They fear the fledgling "freebirth" movement may undo gains in mother-infant mortality. The women, however, believe unassisted childbirth is emotionally and physically the safest option for themselves and their babies.
Some $33 \%$, or 8708 out of 26667 homebirths in the United States in 2007 were not attended by a physician or midwife, up from $30 \%$ in 2005 and $31 \%$ in 2006, according to the US Centers for Disease Control and Prevention (www.cdc.gov/nchs/data/nvsr/nvsr58 /nvsr58_24.pdf). Two-thirds of those deliveries attended by someone other than a physician or midwife in 2006 were reported as "planned" (www.cdc.gov /nchs/data/nvsr/nvsr58/nvsr58_11.pdf).

Canada lacks similar statistics, but a cursory search online turns up a surfeit of websites, forums, chat groups, guides and home videos dedicated to freebirth. Popular parenting website Mothering.com, for example, currently hosts more than 15000 active discussions on unassisted childbirth, or what members call "UC" (www.mothering .com/community).

It's a difficult trend to track with any certainty, not least because advocates of unassisted childbirth aim to avoid interaction with the medical system wherever possible.

While some women forgo prenatal care entirely, others orchestrate a "planned oops" or "accidental" unas- 